January 2015

\title{
Parenting skills and emotional availability: An RCT
}

\author{
Aisha K. Yousafzai \\ Aga Khan University \\ Muneera A. Rasheed \\ Aga Khan University \\ Arjumand Rizvi \\ Aga Khan University \\ Robert Armstrong \\ Aga Khan University, robert.armstrong@aku.edu \\ Zulfiqar A. Bhutta \\ Aga Khan University
}

Follow this and additional works at: https://ecommons.aku.edu/ eastafrica_fhs_mc_paediatr_child_health

Part of the Pediatrics Commons

\section{Recommended Citation}

Yousafzai, A. K., Rasheed, M. A., Rizvi, A., Armstrong, R., Bhutta, Z. A. (2015). Parenting skills and emotional availability: An RCT. Pediatrics, 135(5).

Available at: https://ecommons.aku.edu/eastafrica_fhs_mc_paediatr_child_health/70 


\section{Parenting Skills and Emotional Availability: An RCT}

Aisha K. Yousafzai, PhD”, Muneera A. Rasheed, MSc ${ }^{a}$, Arjumand Rizvi, MSc ${ }^{\mathrm{a}}$, Robert Armstrong, PhD ${ }^{\mathrm{b}}$, Zulfiqar A. Bhutta, PhD

OBJECTIVE: To investigate whether a responsive stimulation intervention delivered to caregivers of young children either alone or integrated with nutrition interventions would benefit parenting skills and emotional availability to promote children's development and growth compared with either a nutrition intervention alone or the usual standard of care.

METHODS: A cluster randomized factorial effectiveness trial was implemented in an impoverished community in Pakistan. The 4 trial arms were control (usual standard of care), responsive stimulation (responsive care and stimulation), enhanced nutrition (education and multiple micronutrients), and a combination of both enriched interventions. The 4 intervention packages were delivered by community health workers to 1489 mother-infant dyads in the first 2 years of life. Parenting skills and emotional availability indexed by mother-child interaction, caregiving environment, knowledge and practices pertaining to early childhood care and feeding, and maternal depressive symptoms were assessed at multiple intervals. An intention-to-treat factorial analysis was conducted.

RESULTS: Intervention groups were comparable at baseline. Responsive stimulation significantly benefitted parenting skills with large effect sizes on mother-child interaction (Cohen's $d$ 0.8), caregiving environment (Cohen's $d$ 0.9-1.0), and knowledge and practices (Cohen's $d$ 0.7-1.1) compared with small-modest significant effects as a result of nutrition intervention on mother-child interaction and caregiving environment only (Cohen's $d 0.4$ and 0.2 , respectively). The combined intervention had a small significant effect on decreasing maternal depressive symptoms over time (Cohen's $d$ 0-0.2).

CONCLUSIONS: A responsive stimulation intervention can promote positive caregiving behaviors among impoverished families. Additional research is needed on interventions to reduce maternal depressive symptoms.

\begin{abstract}
${ }^{a}$ Division of Women and Child Health, Department of Paediatrics and Child Health, Aga Khan University, Karachi, Pakistan; ${ }^{b}$ Medical College, Aga Khan University, Nairobi, Kenya; and ${ }^{C}$ Center for Global Child Health, Hospital for Sick Children, Toronto, Canada

Dr Yousafzai conceptualized the study; developed the protocol, study design, and data collection instruments; coordinated the implementation of the study and oversaw training of the research team; planned analysis; interpreted findings; and drafted the manuscript; Ms Rasheed trained the Community-based Child Development Assessors, oversaw quality assurance of the psychosocial evaluations, contributed to the review of literature, contributed to the interpretation of findings, and critically reviewed drafts of the manuscripts; Ms Rizvi was the statistician for the study and participated in the study design, data analysis, and data interpretation and critically reviewed drafts of the manuscript; Dr Armstrong provided input to the study design and critically reviewed drafts of the manuscripts; and Dr Bhutta conceptualized the study with Dr Yousafzai, provided input to the study design, and critically reviewed drafts of the manuscript.
\end{abstract}

This trial has been registered at www.clinicaltrials.gov (identifier NCT007159636).

www.pediatrics.org/cgi/doi/10.1542/peds.2014-2335

DOI: $10.1542 /$ peds.2014-2335

Accepted for publication Feb 12, 2015

Address correspondence to Aisha K. Yousafzai, PhD, Department of Paediatrics and Child Health, Aga Khan University, Stadium Road P0 B0X 3500, Karachi, 74800, Pakistan. E-mail: aisha.yousafzai@aku. edu
WHAT'S KNOWN ON THIS SUBJECT: Early parenting programs benefit children's development in low- and middle-income countries. However, the extent to which these interventions have a positive impact on parenting skills and their emotional availability is less studied.

WHAT THIS STUDY ADDS: An early child development intervention using play and communication activities to promote caregivers' responsiveness can improve mother-child interactions, caregiving environment, caregiving practices pertaining to development and feeding, and, in combination with a nutrition intervention, support maternal emotional well-being. 
Parenting programs provide families with information and support to enable their child's survival, development, and well-being. ${ }^{1}$ Domains of parenting to support children's health, hygiene and nutrition, stimulation, responsiveness, protection, and socialization may be addressed. ${ }^{2}$ In addition to health and nutrition information, early child development (ECD) programs emphasize promoting stimulation. Low stimulation is a risk for poor child development, particularly for children in low- and middle-income countries. ${ }^{3,4}$ Inadequate resources limit availability of learning materials provided to children, ${ }^{5}$ but interventions using homemade toys or libraries help overcome these barriers. ${ }^{6}$

Responsive parenting (the ability to be aware of a child's signals and provide a timely and developmentally appropriate response) ${ }^{7}$ is a fundamental parenting skill to support children's survival and development. Promoting responsive caregiving behaviors through training 8,9 or using contexts such as shared book reading ${ }^{10}$ or play ${ }^{6}$ have demonstrated improvements in children's development, ${ }^{6}$ maternal mood, ${ }^{9}$ secure infant attachment, ${ }^{9}$ and quality of mother-child interactions. ${ }^{8-10}$ Responsive feeding has shown improvements in maternal verbal responsiveness, ${ }^{11,12}$ child's acceptance of foods, ${ }^{12}$ mouthfuls eaten, ${ }^{11}$ and dietary intake. ${ }^{13}$

A parent's emotional availability influences parenting capacity. Maternal depression is associated with early cessation of breastfeeding, ${ }^{14}$ poor ECD, 15 growth, ${ }^{16}$ and health outcomes. ${ }^{17}$ Interventions addressing maternal depression may improve emotional availability, and participation in parenting programs in low- and middle-income countries shows mixed effects on maternal depression. ${ }^{9,18,19}$
Although there are many approaches to parenting programs, it is recognized that information sharing alone may be insufficient to promote changes in parenting behaviors. The identification of which behavioral change techniques and social support strategies support early childhood care and development needs to be explored further. ${ }^{20}$

There is evidence to show ECD programs in low- and middle-income countries promote children's development, ${ }^{21}$ but theories of change in parenting programs and effects on intended parenting outcomes are reported less frequently. We implemented an ECD and nutrition trial in Pakistan. The intervention effects on child outcomes, published in the Lancet, reported that the ECD intervention improved children's cognition, language, and motor development. ${ }^{22}$ In this component of the study, we sought to address whether these same interventions also changed intended parenting outcomes. We hypothesized that the ECD intervention delivered to caregivers of children in the first 2 years of life either alone or integrated with nutrition interventions would benefit parenting skills and emotional availability.

\section{METHODS}

\section{Study Design}

This trial was conducted with the Lady Health Worker (LHW) Program, a national community-based health service addressing family planning, health, and nutrition, particularly for women and children, living in disadvantaged communities through monthly home visits and community meetings. ${ }^{23}$ A cluster randomized effectiveness trial with a $2 \times 2$ factorial design tested the effectiveness and feasibility of integrating new interventions with routine services to improve ECD and growth outcomes. The 4 trial arms were as follows: (1) control $(n=368)$,

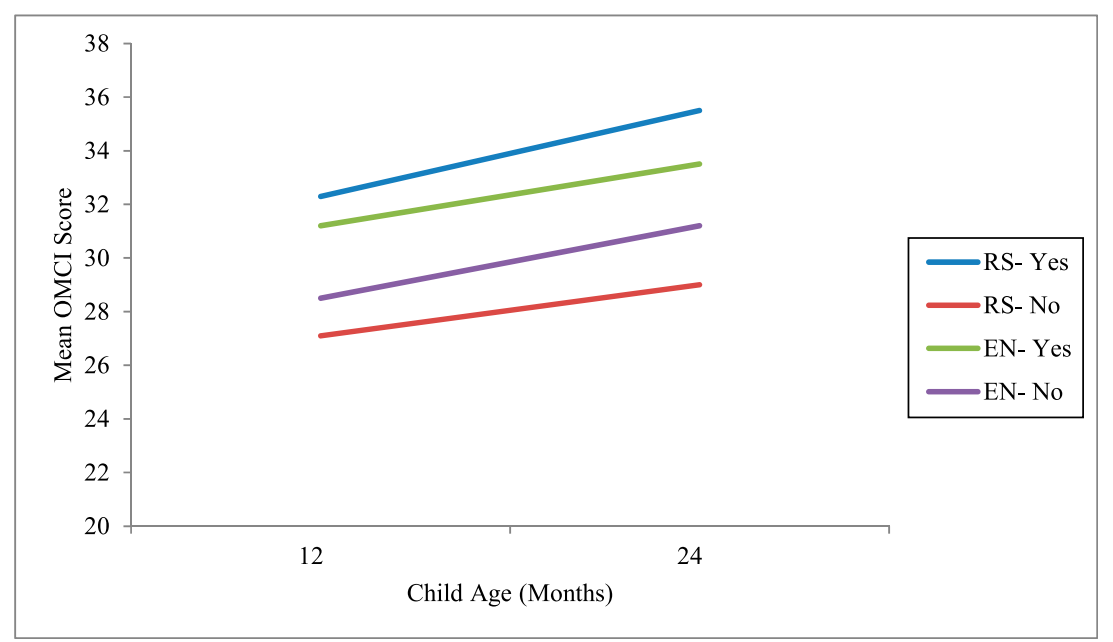

FIGURE 1

Mean scores for mother and child interaction at 12 and 24 months of child age. Twelve months: RS, $n=698$; no RS, $n=665$; EN, $n=661$; no EN, $n=702$. Twenty-four months: RS, $n=708$; no RS, $n=682$ $\mathrm{EN}, n=679$; no EN, $n=711$. The linear mixed-model analysis is adjusted for clustering and controlled for covariates of SES, household food security, maternal education, number of siblings, and child gender. Significant differences at each time point between responsive stimulation and no responsive stimulation $(P<.001)$ and between enhanced nutrition and no enhanced nutrition $(P<.001)$ were observed. There were significant interactions between the 2 interventions at each time point $(P<$ .001). Repeated-measures analysis, controlled for covariates of SES, household food security, maternal education, number of siblings, and child gender showed over time from 12 to 24 months: RS, $\beta 8.0$ (SE 0.6), 95\% confidence interval (CI) 6.9-9.2; EN $\beta$ 5.3 (SE 0.7), 95\% Cl 4.0-6.7; interaction $\beta 5.8$ (SE 0.9), 95\% Cl 4.0-7.5. 
(2) responsive stimulation (RS, $n=$ 383), (3) enhanced nutrition (EN, $n=364$ ), and (4) combined (RS \& EN, $n=374$ ). All 4 trial arms continued to receive the standard health care services provided by LHWs. The LHW was responsible for delivering the intervention package (standard care with or without 1 of the enriched intervention packages) to every child in her catchment aged $<2$ years from June 2009 through March 2012.

Identified by an independent surveillance team, every infant born in the study area in the first year of the trial roll out was eligible for enrolment for the in-depth outcome evaluations when infants were 6,12 , 18 , and 24 months old. A total of 1489 mother-infant dyads were enrolled at birth (up to the first 2.5 months of life) and followed for assessment to 2 years of age (with $7 \%$ attrition). The primary outcomes were child development and child growth. ${ }^{22}$

The trial was implemented in a predominantly rural and impoverished community. Among enrolled children, $40 \%$ came from the poorest households, 32\% lived in households with food insecurity, $68 \%$ had mothers who were illiterate, and $27 \%$ were stunted by 1 year of age. Ethical approval was granted by the Ethics Review Committee of the Aga Khan University. Details on the study design, subjects, trial profile, intervention monitoring and compliance, data collection procedures, and findings on intervention effects on child outcomes and cost-effectiveness are reported elsewhere. ${ }^{22,24}$

\section{Interventions}

The RS intervention was an adaptation of the Care for Child Development (CCD) approach developed by the United Nations Children's Fund (UNICEF) and the World Health Organization, ${ }^{25}$ which uses play and communication activities to promote responsive care. The approach has 2 goals: (1) to help caregivers provide stimulation opportunities to promote children's cognitive, language, motor, and socialemotional skills and (2) using techniques based on Homan's interaction theory, ${ }^{26}$ to enhance responsive care by helping caregivers observe and respond to their child's

TABLE 1 Mean (SD), 95\% Confidence Interval of HOME Inventory Scores for Quality of the Caregiving Environment at 6 and 18 Months of Age

\begin{tabular}{|c|c|c|c|c|c|c|c|}
\hline \multirow[t]{2}{*}{ HOME Subdomain and Total Scores } & \multicolumn{3}{|c|}{ RS Intervention } & \multicolumn{3}{|c|}{ EN Intervention } & \multirow[t]{2}{*}{$P$ Interaction } \\
\hline & Yes & No & $P$ & Yes & No & $P$ & \\
\hline \multicolumn{8}{|l|}{ Age 6 mo } \\
\hline \multirow{2}{*}{ Responsiveness } & $7.2(1.8)$ & $6.8(1.6)$ & .15 & $7.1(1.7)$ & $6.9(1.7)$ & .88 & .23 \\
\hline & $7.0-7.3$ & $6.7-6.9$ & & $6.9-7.2$ & $6.8-7.1$ & & \\
\hline \multirow[t]{2}{*}{ Acceptance } & $6.9(1.0)$ & $6.8(0.9)$ & .64 & $6.8(1.1)$ & $6.9(0.8)$ & .004 & .32 \\
\hline & $6.8-6.9$ & $6.8-6.9$ & & $6.7-6.9$ & $6.9-7.0$ & & \\
\hline \multirow[t]{2}{*}{ Organization } & $3.5(1.2)$ & $3.3(1.2)$ & .93 & $3.6(1.2)$ & $3.2(1.2)$ & .18 & .01 \\
\hline & $3.3-3.6$ & $3.1-3.4$ & & $3.4-3.7$ & $3.0-3.3$ & & \\
\hline \multirow[t]{2}{*}{ Learning materials } & $2.7(1.6)$ & $2.3(1.4)$ & $<.0001$ & $2.5(1.4)$ & $2.6(1.6)$ & .18 & $<.0001$ \\
\hline & $2.5-2.9$ & $2.2-2.5$ & & $2.4-2.6$ & $2.3-2.8$ & & \\
\hline \multirow[t]{2}{*}{ Involvement } & $5.9(1.1)$ & $5.5(1.1)$ & .05 & $5.7(1.2)$ & $5.8(1.1)$ & $<.0001$ & .004 \\
\hline & $5.8-6.0$ & $5.4-5.6$ & & $5.5-5.8$ & $5.6-5.9$ & & \\
\hline \multirow[t]{2}{*}{ Variety } & $2.9(0.9)$ & $2.8(0.8)$ & .02 & $2.6(0.8)$ & $3.1(0.8)$ & $<.0001$ & .05 \\
\hline & $2.8-3.0$ & $2.7-2.9$ & & $2.6-2.7$ & $3.0-3.2$ & & \\
\hline \multirow[t]{2}{*}{ Total } & $29.0(4.4)$ & $27.6(3.7)$ & .002 & $28.2(4.1)$ & $28.4(4.2)$ & .03 & .58 \\
\hline & $28.5-29.5$ & $27.2-28.0$ & & $27.8-28.6$ & $27.9-29.0$ & & \\
\hline \multicolumn{8}{|l|}{ Age 18 mo } \\
\hline \multirow[t]{2}{*}{ Responsiveness } & $8.4(1.8)$ & $7.5(1.6)$ & $<.001$ & $8.1(1.7)$ & $7.9(1.8)$ & .08 & .42 \\
\hline & $8.3-8.6$ & $7.3-7.6$ & & $7.9-8.3$ & $7.6-8.1$ & & \\
\hline \multirow[t]{2}{*}{ Acceptance } & $6.5(0.8)$ & $6.3(0.8)$ & .01 & $6.5(0.8)$ & $6.3(0.8)$ & .002 & .96 \\
\hline & $6.4-6.6$ & $6.2-6.4$ & & $6.5-6.6$ & $6.2-6.4$ & & \\
\hline \multirow[t]{2}{*}{ Organization } & $3.7(1.2)$ & $3.6(1.1)$ & .12 & $3.7(1.1)$ & $3.5(1.1)$ & .03 & .32 \\
\hline & $3.5-0.8$ & $3.4-3.7$ & & $3.6-3.9$ & $3.4-3.7$ & & \\
\hline \multirow[t]{2}{*}{ Learning materials } & $5.0(1.8)$ & $3.3(1.8)$ & $<.0001$ & $4.3(2.0)$ & $4.0(2.0)$ & .16 & .49 \\
\hline & $4.7-5.2$ & $3.1-3.5$ & & $4.0-4.6$ & $3.6-4.4$ & & \\
\hline \multirow[t]{2}{*}{ Involvement } & $6.0(1.4)$ & $5.0(1.6)$ & $<.0001$ & $5.6(1.6)$ & $5.4(1.6)$ & .25 & .99 \\
\hline & $5.9-6.2$ & $4.8-5.1$ & & $5.4-5.8$ & $5.2-5.6$ & & \\
\hline \multirow[t]{2}{*}{ Variety } & $3.2(0.6)$ & $3.0(0.7)$ & $<.0001$ & $3.1(0.7)$ & $3.1(0.7)$ & .78 & .86 \\
\hline & $3.2-3.3$ & $2.9-3.0$ & & $3.0-3.2$ & $3.0-3.2$ & & \\
\hline \multirow{2}{*}{ Total } & $32.8(5.1)$ & $28.0(5.0)$ & $<.0001$ & $31.4(5.5)$ & $30.2(5.4)$ & .02 & .46 \\
\hline & $32.1-33.5$ & $28.0-29.2$ & & $30.5-32.2$ & $29.2-31.1$ & & \\
\hline
\end{tabular}

Six months: RS, $n=699$; no RS, $n=666$; EN, $n=658$; no EN, $n=707$. Eighteen months: RS, $n=702$; no RS, $n=661$; EN, $n=668$; no EN, $n=695$. The linear mixed-model analysis is adjusted for clustering and controlled for covariates of SES, household food security, maternal education, and number of siblings. Child gender was not a significant covariate for the HOME Inventory scores. Repeated-measures analysis, controlled for covariates of SES, household food security, maternal education, and number of siblings showed over time from 6 to 18 months: RS, $\beta 1.42$ (SE 0.36), 95\% confidence interval (Cl) 0.71 to 2.13 ; EN $\beta-0.53$ (SE 0.29 ), $95 \% \mathrm{Cl}-1.1$ to 0.04 ; interaction $\beta-0.09$ (SE 0.47 ), $95 \% \mathrm{Cl}-1.01$ to 0.83 . 
signals through play and communication interactions, leading to changes in sentiments that promote caregiver-child interactions. The LHW suggested developmentally appropriate activities for caregivers to try with their child and then proceeded to coach caregivers by helping them to observe their child's signals and respond appropriately to experience a successful interaction (see the Supplemental Information for details on adaptation).

The EN intervention enriched the existing nutrition education curriculum in the LHW program. This was achieved by the addition of responsive feeding messages (including recognizing and responding to early cues of hunger, communication, encouragement, and patience during feeding and independent feeding), distribution of a multiple micronutrient powder (MNP) for children aged 6-24 months to address the prevalent micronutrient deficiencies in the population, ${ }^{27}$ helping LHWs to link nutrition and health messages, and training LHWs to move away from a didactic approach of delivering nutrition education to one whereby she seeks to understand the situation of the child and family, and responds appropriately. The MNP distribution included instruction on how to mix the powder in the prepared semisolid food for the case child.

The CCD approach was delivered through monthly group meetings and home visits. The EN intervention supplemented the nutrition education service delivered by LHWs in routine monthly home visits. The combined trial arm received a combination of both interventions (see theory of change in Supplemental Fig 6).

\section{Measures and Procedures}

Data were collected by trained data collectors, independent of the intervention implementation team, and masked to intervention assignment. All data collectors had completed secondary education, and the specialist team collecting child development-related data

(Community-based Child

Development Assessors [CCDAs]) had work experience in either teaching or community development or held a bachelor's degree in psychology. After baseline training, refresher training was provided every 6 months, and each assessor received a monthly supervisory visit with feedback.

Household demographic and socioeconomic status (SES) information was collected from each enrolled household. ${ }^{22}$ For this component of the study, secondary outcomes related to parenting skills and emotional availability were mother-child interaction (an indicator of maternal responsive caregiving behaviors), the quality of the caregiving environment, maternal caregiving knowledge and practices pertaining to development and feeding, and maternal depressive symptoms. Uniform questionnaires were administered in each arm of the trial in Sindhi. Language translation

TABLE 2 Mean (SD), 95\% Confidence Interval of Maternal Knowledge and Practices on Care for Child Development at 12 and 24 Months of Age

\begin{tabular}{|c|c|c|c|c|c|c|c|}
\hline \multirow[t]{2}{*}{ Maternal Knowledge and Practice } & \multicolumn{3}{|c|}{ RS Intervention } & \multicolumn{3}{|c|}{ EN Intervention } & \multirow[t]{2}{*}{$P$ Interaction } \\
\hline & Yes & No & $P$ & Yes & No & $P$ & \\
\hline \multicolumn{8}{|l|}{ Baseline } \\
\hline \multirow[t]{2}{*}{ Knowledge } & $9.1(2.8)$ & $8.9(3.2)$ & .46 & $8.9(2.9)$ & $9.2(3.1)$ & .003 & .034 \\
\hline & $8.9-9.3$ & $8.7-9.2$ & & $8.7-9.1$ & $8.9-9.4$ & & \\
\hline \multirow[t]{2}{*}{ Practice } & $8.1(4.9)$ & $9.3(5.2)$ & $<.0001$ & $8.2(4.9)$ & $9.2(5.3)$ & $<.0001$ & .001 \\
\hline & $7.7-8.5$ & $8.8-9.8$ & & $7.8-8.6$ & $8.7-9.7$ & & \\
\hline \multirow[t]{2}{*}{ Total } & $17.2(6.5)$ & $18.3(6.9)$ & $<.0001$ & $17.2(6.4)$ & $18.4(6.9)$ & $<.0001$ & .001 \\
\hline & $16.7-17.7$ & $17.7-18.9$ & & $16.6-17.6$ & $17.7-19.0$ & & \\
\hline \multicolumn{8}{|l|}{$12 \mathrm{mo}$} \\
\hline \multirow[t]{2}{*}{ Knowledge } & $11.3(2.2)$ & $10.7(2.4)$ & $<.0001$ & $11.0(2.0)$ & $10.9(2.4)$ & .04 & .008 \\
\hline & $11.1-11.5$ & $10.5-10.9$ & & $10.9-11.2$ & $10.7-11.2$ & & \\
\hline \multirow[t]{2}{*}{ Practice } & $13.1(2.3)$ & $12.3(3.0)$ & .14 & $12.2(2.4)$ & $13.1(2.0)$ & $<.0001$ & .004 \\
\hline & $12.9-13.3$ & $11.9-12.6$ & & $12.0-12.5$ & $12.9-13.3$ & & \\
\hline \multirow[t]{2}{*}{ Total } & $24.4(3.6)$ & $22.9(4.3)$ & $<.0001$ & $23.3(3.4)$ & $24.0(3.3)$ & .002 & 625 \\
\hline & $24.0-24.7$ & $22.5-23.3$ & & $22.9-23.7$ & $23.6-24.4$ & & \\
\hline \multicolumn{8}{|l|}{$24 \mathrm{mo}$} \\
\hline \multirow[t]{2}{*}{ Knowledge } & $12.3(2.2)$ & $10.8(2.6)$ & $<.0001$ & $11.3(2.6)$ & $11.8(2.5)$ & .11 & .05 \\
\hline & $12.1-12.5$ & $10.6-11.0$ & & $11.0-11.6$ & $11.5-12.2$ & & \\
\hline \multirow[t]{2}{*}{ Practice } & $13.8(1.9)$ & $12.4(2.1)$ & $<.0001$ & $13.0(2.8)$ & $13.2(2.2)$ & .03 & $<.0001$ \\
\hline & $13.5-14.0$ & $12.2-12.6$ & & $12.8-13.2$ & $12.8-13.5$ & & \\
\hline \multirow[t]{2}{*}{ Total } & 26.1 (3.3) & $23.2(3.5)$ & $<.0001$ & $24.3(4.5)$ & $25.0(4.0)$ & .65 & $<.0001$ \\
\hline & $25.7-26.4$ & $22.9-23.5$ & & $23.9-24.7$ & $24.3-25.7$ & & \\
\hline
\end{tabular}

Baseline: RS, $n=757$; no RS, $n=732$; EN, $n=737$; no EN, $n=752$. Twelve months: RS, $n=701$; no RS, $n=665$; EN, $n=661$; no EN, $n=705$. Twenty-four months: RS, $n=708$; no RS, $n=682$; EN, $n=679$; no EN, $n=711$. The linear mixed model analysis is adjusted for clustering and controlled for covariates of SES, maternal education, number of siblings, and child gender (however, child gender is not a significant covariate for knowledge scores and total scores, and number of siblings is not a significant covariate for practice scores). Repeated-measures analysis, controlled for covariates of SES, household food security, maternal education, number of siblings, and child gender, showed over time from 12 to 24 months: RS, $\beta 1.7$ (SE 0.3 ), 95\% confidence interval (CI) 1.1 to 2.3 ; EN, $\beta-0.6$ (SE 0.3), $95 \% \mathrm{Cl}-1.3$ to 0.02 ; interaction $\beta-0.7$ (SE 0.3 ), $95 \% \mathrm{Cl}-1.3$ to 0.003 . 
and cultural modification protocols were followed to ensure retention of the conceptual integrity of items. ${ }^{28}$

Maternal responsive caregiving behaviors were assessed when children were 12 and 24 months old using the Observation of Mother and Child Interaction (OMCI) tool. ${ }^{29}$ The CCDAs observed a live 5-minute interaction while mother and child played together with a picture book. The tool comprises 19 items covering maternal affect, maternal touch, maternal verbalization, sensitivity and contingent responses, scaffolding, language stimulation, focus, child affect, child focus, child's communication efforts, and mutual enjoyment. The OMCI items were identified from a framework on responsive parenting proposed by Landry and colleagues. ${ }^{30}$ The scoring format is based on the frequency of the occurrence of behaviors with higher scores indicating more responsive interactions.

Interobserver agreement between CCDAs and the supervisor using the Bland-Altman test was moderate to high (at 12 months for the mother, $n=81, r=0.82, P<.001$, and for the child, $n=81, r=0.82, P<.001$; at 24 months for the mother, $n=154$, $r=0.58, P<.001$, and for the child, $n=154, r=0.77, P<.001)$.

The Home Observation for the Measurement of the Environment (HOME) Inventory assessed the caregiving environment of children at 6 and 18 months old. The HOME Inventory is a measure of the quality and quantity of stimulation and support in the child's home. ${ }^{31}$ In this study, the original 45 items were retained with some cultural modifications determined after extensive piloting. Interobserver agreement between CCDAs and the supervisor using the Bland-Altman test was high ( $n=96, r=0.99$, $P<.001)$.

Maternal knowledge and practices about children's development were collected by using structured questionnaires when children were 12 and 24 months old. Questions included a key item from the ECD module of the UNICEF Multiple Cluster Index Surveys (In the past 3 days, did you or any household member over 15 years of age engage in any of the following activities with your child: read books or looked at pictures together, told stories, sang songs, took child outside of the home compound, play with child, named or counted or drew things to or with child). ${ }^{32}$ In a separate questionnaire, information on infant and young child feeding indicators was collected by maternal report at baseline, and when infants and young children were 6 , 12,18 , and 24 months old. ${ }^{33}$

Maternal depressive symptoms were assessed using the self-reporting questionnaire (SRQ-20). The SRQ-20 was administered to mothers at
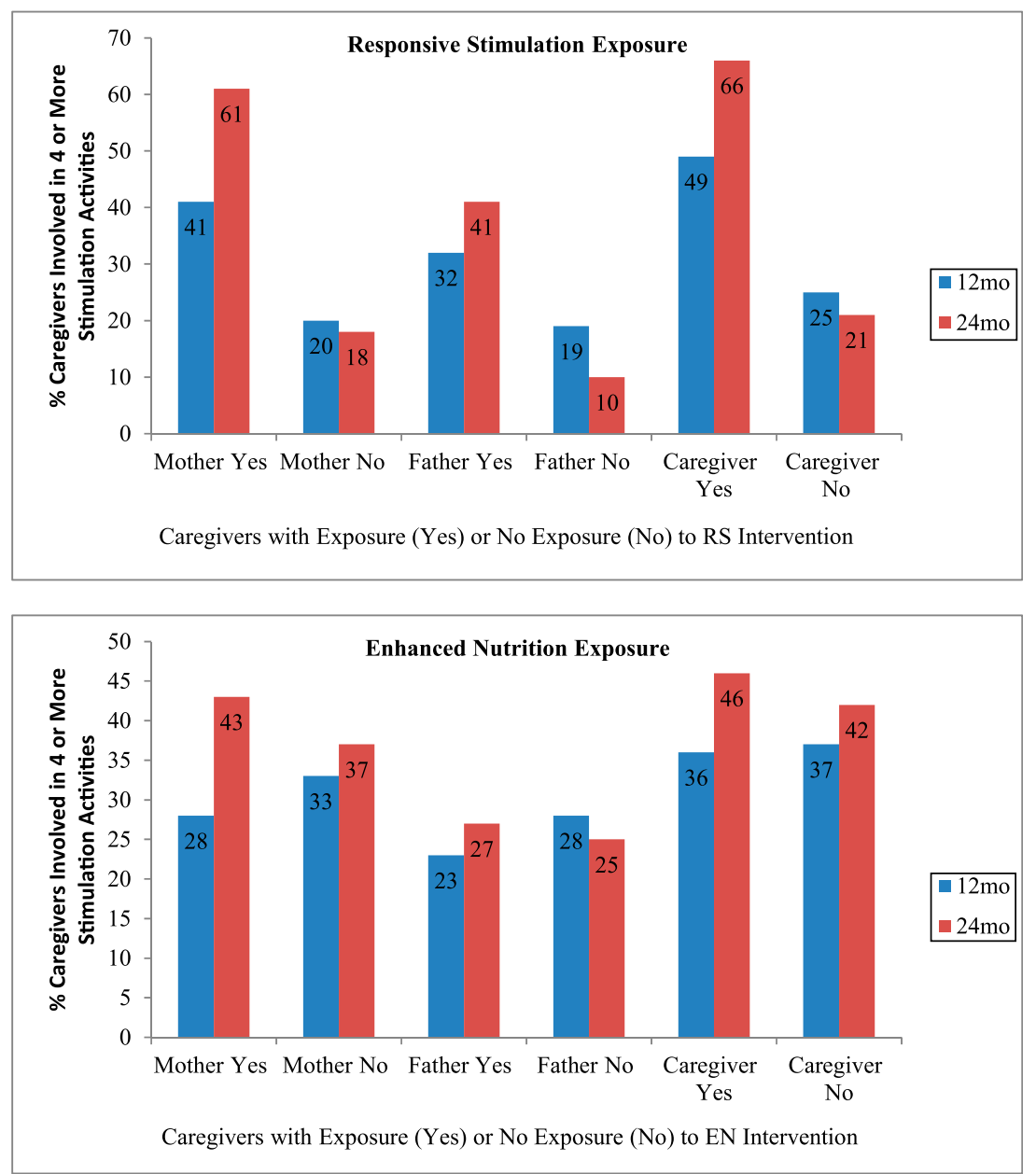

FIGURE 2

Prevalence of caregivers involved in $\geq 4$ stimulation activities (early learning activities) with their young children in the previous 3 days. Source: Maternal Knowledge and Practices Questionnaire, UNICEF Multiple Indicator Cluster Surveys item. Caregiver is another adult caregiver apart from the parent. Cluster adjusted generalized estimating equation analysis controlling for SES, household food security, maternal education, number of siblings, and child gender indicate the following: (1) Mothers were significantly more involved over time (12-24 months) in RS versus no RS exposure $(P<.0001)$ and in EN versus no NE exposure $(P=.002)$, and there was significant interaction between the 2 interventions $(P=.001)$. (2) Fathers were significantly more involved over time (12-24 months) in RS versus no RS exposure $(P<.0001)$ and in EN versus no EN exposure $(P<.0001)$, and there was significant interaction between the 2 interventions $(P=.0001)$. (3) Caregivers were significantly more involved over time $(12-24$ months) in RS versus no RS exposure $(P<.0001)$ but not in EN versus no EN exposure $(P=.08)$, and there was significant interaction between the 2 interventions $(P=.02)$. 
baseline and when children were 6 , 12,18 , and 24 months old. The SRQ20 comprises 20 items designed to identify mental distress, including depression and anxiety-related symptoms. ${ }^{34}$ Validity and reliability for postnatal depression for the Urdu version have been evaluated in Pakistan, and a score $\geq 9$ indicates risk of postnatal depression. ${ }^{35,36}$ In this study, the Urdu version was translated to Sindhi. Interobserver agreement between CCDAs and the supervisor using the Bland-Altman test was high ( $n=51, r=0.99, P<.001)$.

\section{Statistical Analysis}

Statistical analysis was performed by using the Statistical Product and Services Solution, Version 15.0. All analyses reported are adjusted for clustering effect by using generalized estimating equations. An intention-totreat analysis to determine the effect of intervention exposure on parenting skills and emotional availability was followed. First, we assessed whether the outcomes were different between the 2 interventions of the factorial design (RS versus no RS, and EN versus no $\mathrm{EN}$ ) at each measurement interval by using linear mixed models and generalized estimating equations controlling for specified confounding variables. Interactions between the

2 interventions were tested for significance. Second, repeatedmeasures analyses were conducted to assess the effect of intervention over time compared with the control group controlling for confounding variables. Third, the effect sizes (Cohen's $d$ ) for the treatment arms were calculated for significant outcomes by taking the difference in adjusted means between treatment and control group over the pooled SD.

\section{RESULTS}

Baseline characteristics (household SES, household food security, gender, enrollment age in months, birth order, and growth status at enrollment) were comparable between intervention exposures; however, significant differences were found in maternal education status, and this is controlled for in the analysis of all intervention effects. ${ }^{22}$

\section{Mother-Child Interaction}

Mother-child dyads exposed to RS compared with no RS had significantly higher mean scores at 12 months (mean 32.3 [SD 8.3] vs mean 27.1 [SD 8.2], $P<.0001$ ) and 24 months of age (mean 35.5 [SD 9.1] vs mean 29.0 [SD 9.9], $P<.001$ ).

Similarly, mother-child dyads exposed to EN compared with no EN had significantly higher mean scores at 12 months (mean 31.2 [SD 8.0] vs mean 28.5 [SD 9.7], $P<.0001$ ) and
24 months of age (mean 33.5 [SD 9.0] vs mean 31.2 [SD 10.3], $P<.001$ ). A significant interaction was observed between the 2 interventions at each measurement interval, indicating an additive benefit to the combined intervention $(P<.001$; Fig 1$)$. Repeated-measures analysis showed a significant benefit over time on mother-child interaction for RS, EN, and the combined intervention.

\section{Caregiving Environment}

At 6 months of child age, mothers exposed to RS had significantly higher total mean HOME score compared with mothers not exposed to RS $(P=.002)$. The categories of "learning
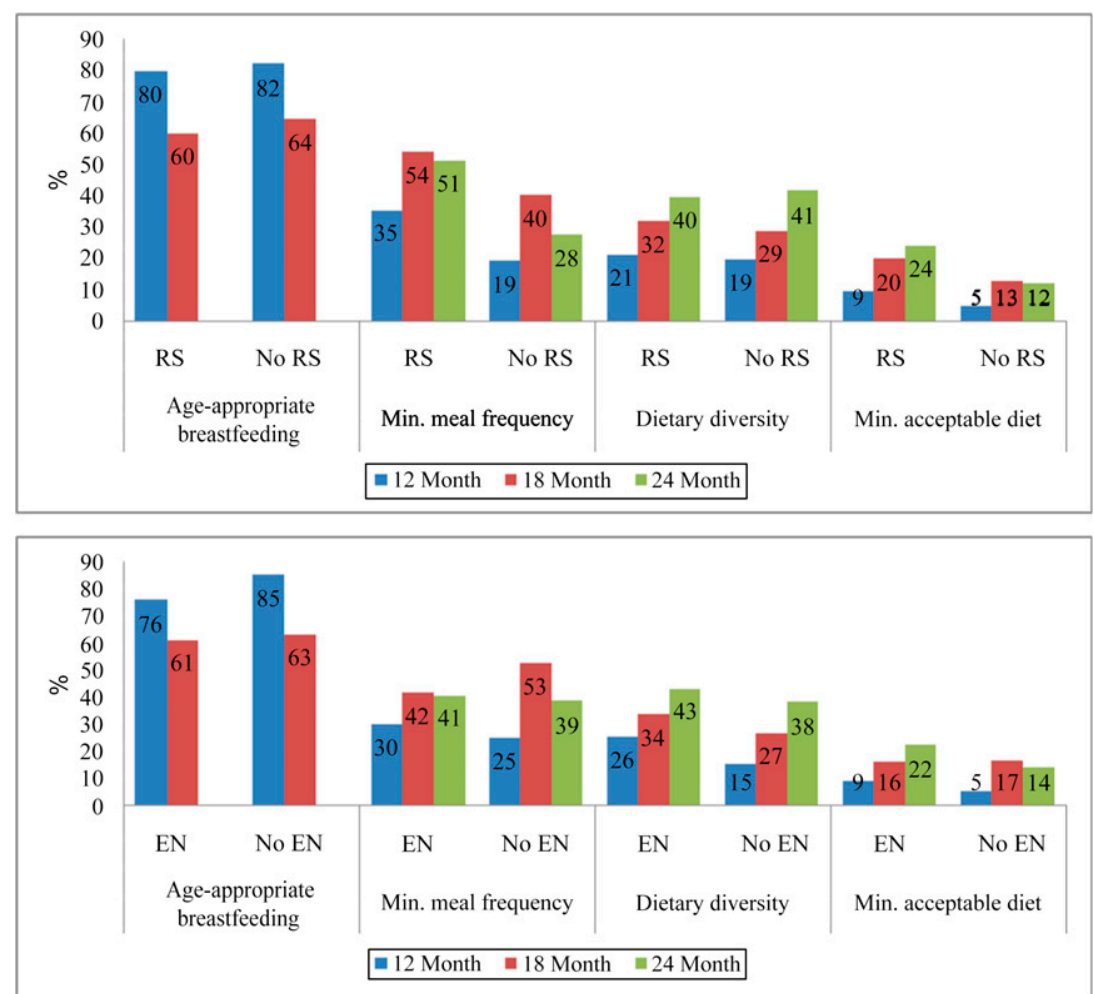

FIGURE 3

Prevalence of age appropriate feeding practices as measured by the World Health Organization infant and young child feeding indicators. Cluster-adjusted generalized estimating equation analysis controlling for SES, household food security, maternal education, number of siblings, and child gender indicate the following: (1) Age-appropriate breastfeeding over time in RS versus no RS exposure was not significant $(P<.91)$; in EN versus no EN exposure, it was significant $(P<.0001)$ and interaction between the 2 interventions was not significant $(P=.44)$. (2) Minimum meal frequency was significantly more over time in RS versus no RS exposure $(P<.0001)$, but not in EN versus no $\mathrm{EN}(P=.59)$, and there was no significant interaction between the 2 interventions $(P=$ .21). (3) Dietary diversity, over time, was not significantly better in RS versus no RS exposure $(P=$ .52) but was significantly better in EN versus no EN $(P=.001)$, and there was no significant interaction between the 2 interventions $(P=.48)$. (4) Minimum acceptable diet over time was significantly better in RS versus no RS exposure $(P<.0001)$, but not significant in EN versus no EN $(P=.33)$, and there was no significant interaction between the 2 interventions $(P=.29)$. 
materials" (an indicator of the variety of toys and books accessible to the child), "involvement" (an indicator of mother's involvement in learning and play), and "variety" (an indicator of the variety of learning opportunities provided to the child) scored significantly higher in the exposed group $(P \leq .05)$. By 18 months of child age, mothers exposed to RS had significantly higher mean scores in all categories (except for "organization," an indicator of routine and safety at home). For the EN intervention, there were significant differences in the total mean HOME score between exposed and not exposed mothers at 6 months $(P=.03)$ and 18 months $(P=.02)$ of infant and young child age. However, there was no significant interaction effect at either 6 or 18 months of age, indicating no additive benefit to the combined intervention (Table 1). Repeated measures analysis showed a significant benefit on HOME Inventory score from 6 to 18 months for RS alone.

\section{Maternal Knowledge and Practices}

Summary scores (knowledge and practice) pertaining to CCD at 12 and 24 months of child age were significantly higher among mothers exposed to RS compared with not exposed mothers $(P<.0001)$ and lower among mothers exposed to EN compared with not exposed mothers (12 months, $P<.0001 ; 24$ months, $P<.002$ ). Significant interaction was observed between RS and EN interventions by 24 months $(P<$ $.0001)$, indicating an additive benefit to the combined intervention (Table 2). Repeated-measures analysis showed a significant benefit from 12 to 24 months for RS alone. Figure 2 shows the number of caregivers (mothers, fathers, and other adult caregivers) involved in $\geq 4$ stimulation activities with their child over a 3-day period, over time, was significantly higher among caregivers exposed to RS and EN with additive benefits to the combined intervention.
With respect to infant and young child feeding indicators, exposure to EN showed over time a greater proportion of mothers practicing ageappropriate breastfeeding $(P<$ $.0001)$ and providing diverse diets $(P=.001)$ compared with no EN. The provision of minimum meal frequency and minimum acceptable diet over time were significantly better among mothers exposed to RS $(P<.0001)$. There were no significant interactions observed between the 2 interventions (Fig 3).

\section{Maternal Depressive Symptoms}

At baseline, among the 1489 enrolled mothers, $29 \%$ had a SRQ-20 score indicative of high depressive symptoms $(\geq 9)$ and $12 \%$ expressed suicide ideation. The prevalence of maternal depressive symptoms increased in the period of follow-up for both interventions (Fig 4). Analysis of intervention effects show at 6 months, mothers exposed to RS compared with no RS and EN compared with no EN had significantly lower mean SRQ-20 scores $(P<.004$ and $P<.05$, respectively), but no significant interaction was observed between the interventions. However, by 24 months of child age, a significant interaction was observed between the interventions indicating an additive benefit to the combined intervention $(P=0.02$; Table 3$)$. Repeatedmeasures analyses suggest a significant protective benefit
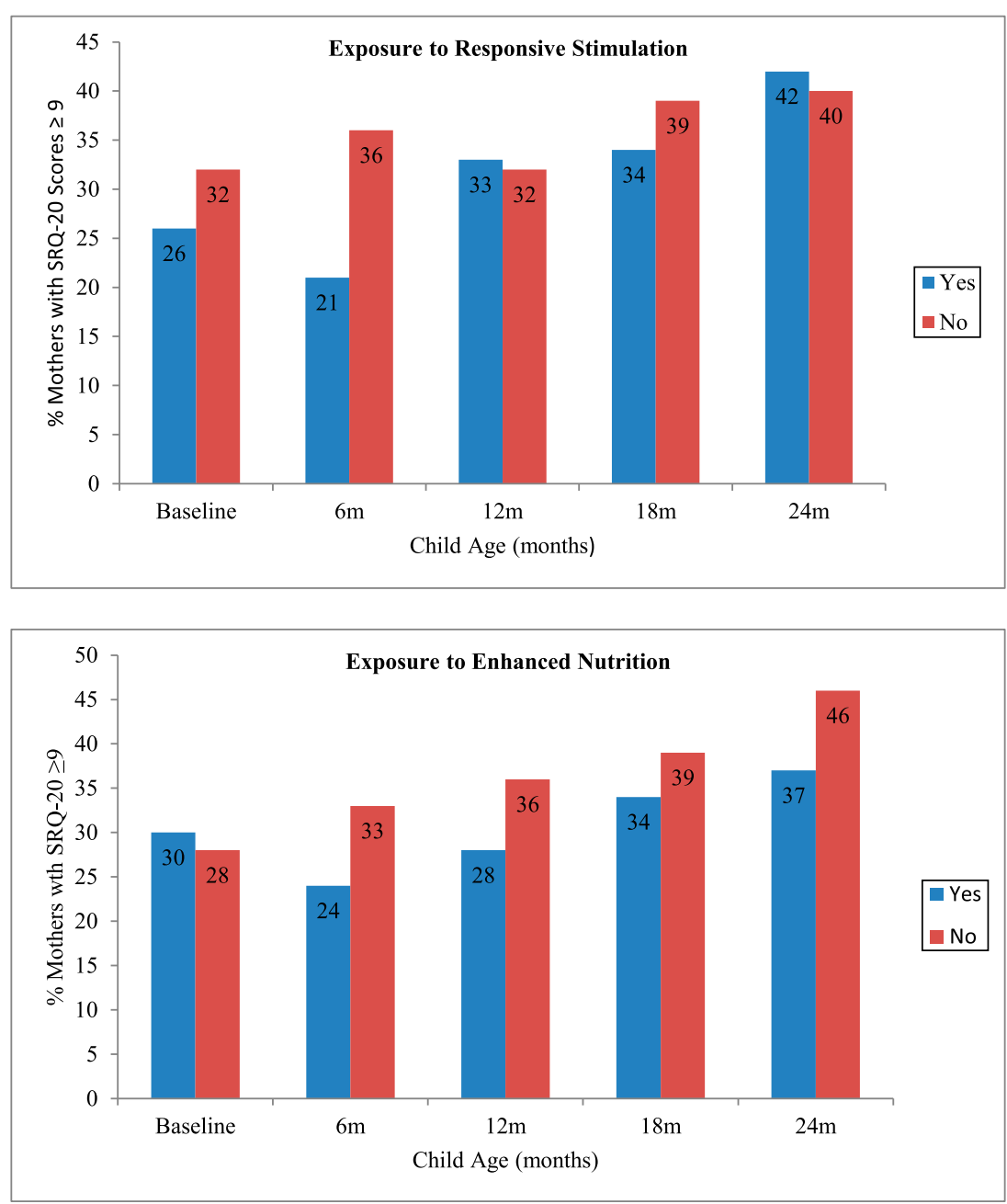

FIGURE 4

Prevalence of maternal depressive symptoms over time in different intervention exposure groups (SRQ-20 score $\geq 9$ ). 
(decline in SRQ-20 score) over time for the combined intervention.

Table 4 shows the treatment effect sizes on the significant outcomes at the study end point. Significant effects are large for both trial arms exposed to RS in all caregiving outcomes (Cohen's $d$ 0.7-1.1). For maternal depressive symptoms, only the combined intervention has a small significant effect. For EN, small to modest significant effect sizes are observed for care environment and mother-child interaction (Cohen's d 0.2-0.4).

\section{DISCUSSION}

By 24 months of child age, significant benefits with moderate-large effect sizes were observed as a result of RS exposure on mother-child interaction, care environment, and knowledge and practices pertaining to development; significant benefits with small-modest effect sizes were observed for mother-child interaction and care environment as a result of EN exposure. Although additive benefits were seen on mother-child interaction and knowledge and practices pertaining to development in the combined intervention, there were no significant differences in the effect sizes with respect to RS alone or RS combined with EN. In agreement with the hypothesis, RS benefitted parenting outcomes with significant impact, and there was no harm in the combination. The added advantage of the combined intervention was a small, significant effect on maternal depressive symptoms.

Benefits on maternal responsive caregiving behaviors were also seen in previous interventions in low- and middle-income countries. ${ }^{8,9}$ Inclusion of responsive care and responsive feeding messages in the RS intervention and responsive feeding in the EN intervention benefited both interventions, which may explain in part some benefits to feeding practices as a result of RS exposure. Caregivers in the EN group did not receive responsive care advice using the same behavioral change technique, which was guided by the developmental literature (ie, rehearsal and feedback on interaction during play and daily care activities), as the RS group received; however, application of this technique for responsive feeding is worth exploring in future research to strengthen the impact of nutrition counseling on

TABLE 3 Mean (SD), 95\% Confidence Interval of SRQ-20 Scores for Maternal Psychosocial Distress at Baseline, 6, 12, 18, and 24 Months of Age

\begin{tabular}{|c|c|c|c|c|c|c|c|}
\hline \multirow[t]{2}{*}{ Age, mo } & \multicolumn{3}{|c|}{ RS Intervention } & \multicolumn{3}{|c|}{ EN Intervention } & \multirow[t]{2}{*}{$P$ Interaction } \\
\hline & Yes & No & $P$ & Yes & No & $P$ & \\
\hline \multirow[t]{2}{*}{ Baseline } & $6.4(3.6)$ & $6.8(4.1)$ & .91 & $6.5(4.1)$ & $6.7(3.6)$ & .34 & .08 \\
\hline & $6.0-6.7$ & $6.4-7.2$ & & $6.1-6.9$ & $6.3-7.0$ & & \\
\hline \multirow[t]{2}{*}{6} & $5.6(4.0)$ & $7.0(4.6)$ & .004 & $5.6(4.5)$ & $6.8(4.1)$ & .05 & .27 \\
\hline & $5.1-6.1$ & $6.6-7.4$ & & $5.1-6.2$ & $6.4-7.3$ & & \\
\hline \multirow[t]{2}{*}{12} & $6.7(4.6)$ & $6.6(4.4)$ & $<.0001$ & $6.2(4.6)$ & $7.0(4.3)$ & .26 & $<.0001$ \\
\hline & $6.2-7.2$ & $6.2-6.9$ & & $5.7-6.7$ & $6.7-7.4$ & & \\
\hline \multirow[t]{2}{*}{18} & $6.9(4.9)$ & $7.6(5.3)$ & .21 & $6.8(5.2)$ & $7.6(5.0)$ & .35 & .51 \\
\hline & $6.3-7.4$ & $7.2-8.0$ & & $6.3-7.3$ & $7.1-8.1$ & & \\
\hline \multirow[t]{2}{*}{24} & $7.6(5.1)$ & $7.6(5.5)$ & .13 & $6.9(5.3)$ & $8.3(5.2)$ & .25 & .02 \\
\hline & $7.0-8.2$ & $7.2-8.1$ & & $6.4-7.4$ & $7.9-8.7$ & & \\
\hline
\end{tabular}

Baseline: RS, $n=757$; no RS, $n=732$; EN, $n=659$; no EN, $n=706$. Six months: RS, $n=700$; no RS, $n=665$; EN, $n=659$; no EN $n=706$. Twelve months: RS, $n=701$; no RS, $n=665$; $\mathrm{EN}, n=661$; no EN, $n=705$. Eighteen months: RS, $n=702$; no RS, $n=$ 661; EN, $n=668$; no EN, $n=695$. Twenty-four months: RS, $n=708$; no RS, $n=682$; EN, $n=679$; no EN, $n=711$. The linearmixed model analysis is adjusted for clustering and controlled for covariates of SES, household food security, maternal education, and number of siblings. Child gender was not a significant covariate for maternal psychosocial distress outcome. Repeated-measures analyses, controlled for covariates of SES, household food security, maternal education, and number of siblings, showed over time from baseline to 24 months: RS, $\beta 0.10$ (SE 0.31), 95\% confidence interval (CI) -0.51 to -0.71 ; EN, $\beta 0.47$ (SE 0.37), $95 \% \mathrm{Cl}-0.25$ to 1.19 ; interaction $\beta-1.07$ (SE 0.49 ), $95 \%$ confidence interval -2.02 to -0.12 .

responsive parenting behaviors. Whereas Landry and colleagues found parents were able to demonstrate responsiveness in a shared reading activity by transferring skills learned in other activities, ${ }^{10}$ in this population, it might be necessary to ensure adequate rehearsal of skills for responsiveness across a range of specific activities.

Enrichment of home stimulation for children's development was shown in both interventions, but with greater impact as a result of the $\mathrm{RS}$ as measured by the HOME Inventory. Specifically in the RS exposure, early benefits were observed at 6 months in categories of provision of stimulation opportunities and learning materials, but by 18 months, caregivers' acceptance,

responsiveness, and involvement had also improved, suggesting duration of intervention exposure might benefit various domains of parenting. Paternal involvement in play also increased over time, which may have been the result of family communication about the intervention given that LHWs specifically reached female caregivers.

The group-based delivery strategy and behavior change techniques (eg, problem solving and social support) were intended to support mothers and contribute to the reduction in maternal depressive symptoms. In this study, we found the combined intervention had a small benefit on maternal depression. Data from previous research demonstrate mixed results. In South Africa, early benefits to reducing maternal depressive symptoms were observed, but these were no longer evident at later time points, ${ }^{9}$ whereas in Bangladesh, mothers who participated in twicemonthly groups compared with home or clinic contacts had reduced symptoms of maternal depression. ${ }^{18}$ In Jamaica, maternal depressive 
TABLE 4 The Effect Size of the Treatment Arms on Caregiving Capacity at End Time Point

\begin{tabular}{|c|c|c|c|c|c|}
\hline \multirow[t]{2}{*}{ Outcome } & \multirow[t]{2}{*}{ Evaluation Tool } & \multirow{2}{*}{$\begin{array}{l}\text { End Point Evaluation } \\
\text { (Child Age, mo) }\end{array}$} & \multicolumn{3}{|c|}{ Cohen's $d$ (Effect Size) for Each Intervention Group (95\% Cl) } \\
\hline & & & $\mathrm{RS}+\mathrm{EN}$ & RS & EN \\
\hline Maternal psychosocial distress & SRQ-20 & 24 & $-0.2(-0.4$ to -0.1$)$ & $0.1(0.0$ to 0.3$)$ & $-0.1(-0.2$ to 0.1$)$ \\
\hline Mother sensitivity and responsiveness & $\mathrm{OMCl}$ & 24 & 0.8 (0.6 to 0.9$)$ & 0.8 (0.6 to 0.9$)$ & $0.4(0.2$ to 0.5$)$ \\
\hline Care environment & HOME Inventory & 18 & $1.0(0.8$ to 1.2$)$ & $0.9(0.7$ to 1.0$)$ & $0.2(0.0$ to 0.3$)$ \\
\hline Care for child development & Questionnaire (maternal report) & 24 & $0.7(0.5$ to 0.8$)$ & $1.1(0.9$ to 1.3$)$ & $0.1(-0.1$ to 0.2$)$ \\
\hline
\end{tabular}

Effect size was calculated as the difference in mean scores between treatment and control arms over the pooled SD score. Analysis was adjusted for clustering and controlled for covariates of SES, household food security, maternal education, and number of siblings by using generalized estimating equations. The $5 \%$ confidence intervals (CIs) indicate significance compared with control.

symptoms were reduced as a result of participation in a home visiting stimulation program ${ }^{19}$ but not in an earlier ECD intervention study in Pakistan. ${ }^{37}$ In contexts such as the current study site, the prevalence of maternal depressive symptoms is high and likely to be the result of multiple issues not captured in our data (eg, domestic violence). More research is needed to better understand how to address the needs of both children and mothers in combined packages addressing maternal depression and ECD.

There are measurement limitations in this study. We did not measure responsive feeding behaviors, which would have been informative about whether this message was practiced in both interventions. Furthermore, changes in the household with respect to care for the child and support of the mother relied only on maternal reports rather than data collected from family members or household observations.

However, the CCD approach, adapted for an impoverished community in Pakistan and delivered by LHWs in an existing community health service, does benefit important components of caregiving capacity associated with healthy ECD and growth. These results might be generalizable to similar populations. The use of multiple behavioral change techniques appeared supportive, ${ }^{20}$ but future research can explore how specific behavioral change techniques mediate outcomes of care and maternal emotional availability.

\section{CONCLUSIONS}

The CCD approach improved maternal responsive caregiving behaviors, mother-child interactions, quality of the home stimulation environment, parental knowledge and involvement in children's development, and supported improvements in young child feeding practices. We recommend that adaptation of the generic curriculum considers the context of caregivers and includes multiple behavioral change techniques to optimize beneficial caregiving behaviors.

\section{ACKNOWLEDGMENTS}

We thank the LHW Program for its partnership in this study. We are grateful to all the mothers and families in district Naushero Feroze, Sindh, who consented to be interviewed and without whom this study would not have been possible. We also thank the study staff including Amjad Hussain, Javed Memon, Saima Siyal, the data collection research team, the CCDAs, and ECD facilitators.

PEDIATRICS (ISSN Numbers: Print, 0031-4005; Online, 1098-4275)

Copyright @ 2015 by the American Academy of Pediatrics

FINANCIAL DISCLOSURE: The authors have indicated they have no financial relationships relevant to this article to disclose.

FUNDING: Supported by the United Nations Children's Fund

POTENTIAL CONFLICT OF INTEREST: The authors have indicated they have no potential conflicts of interest to disclose.

\section{REFERENCES}

1. Britto PR, Ulkuer N. Child development in developing countries: child rights and policy implications. Child Dev. 2012;83(1): 92-103

2. Bradley RH, Crowyn RF. Caring for children around the world: a view from HOME. Int J Behav Dev. 2005;29(6): 468-478
3. Walker SP, Wachs TD, GranthamMcGregor S, et al. Inequality in early childhood: risk and protective factors for early child development. Lancet. 2011; 378(9799):1325-1338

4. Walker SP, Wachs TD, Gardner JM, et al; International Child Development Steering Group. Child development: risk factors for adverse outcomes in developing countries. Lancet. 2007;369(9556): 145-157

5. Bradley RH, Putnick DL. Housing quality and access to material and learning resources within the home environment in developing countries. Child Dev. 2012; 83(1):76-91 
6. Gardner JM, Walker SP, Powell CA, Grantham-McGregor S. A randomized controlled trial of a home-visiting intervention on cognition and behavior in term low birth weight infants. J Pediatr. 2003;143(5): 634-639

7. Eshel N, Daelmans B, de Mello MC, Martines J. Responsive parenting: interventions and outcomes. Bull World Health Organ. 2006;84(12):991-998

8. Boivin MJ, Bangirana P, Nakasujja N et al. A year-long caregiver training program to improve neurocognition in preschool Ugandan HIV-exposed children. J Dev Behav Pediatr. 2013;34(4): 269-278

9. Cooper PJ, Tomlinson M, Swartz L, et al. Improving quality of mother-infant relationship and infant attachment in socioeconomically deprived community in South Africa: randomised controlled trial. BMJ. 2009;338:b974

10. Landry SH, Smith KE, Swank PR, Zucker T, Crawford AD, Solari EF. The effects of a responsive parenting intervention on parent-child interactions during shared book reading. Dev Psychol. 2012;48(4): 969-986

11. Aboud FE, Akhter S. A cluster-randomized evaluation of a responsive stimulation and feeding intervention in Bangladesh. Pediatrics. 2011;127(5). Available at: www.pediatrics.org/cgi/content/full/127/ 5/e1191

12. Aboud FE, Shafique S, Akhter S. A responsive feeding intervention increases children's self-feeding and maternal responsiveness but not weight gain. J Nutr. 2009;139(9): 1738-1743

13. Vazir S, Engle P, Balakrishna N, et al. Cluster-randomized trial on complementary and responsive feeding education to caregivers found improved dietary intake, growth and development among rural Indian toddlers. Matern Child Nutr. 2013;9(1): 99-117

14. Wachs TD, Black MM, Engle PL. Maternal depression: a global threat to children's health, development and behavior and to human rights. Child Dev Perspect. 2009;3:51-59

15. Hamadani JD, Tofail F, Hilaly A, et al. Association of postpartum maternal morbidities with children's mental, psychomotor and language development in rural Bangladesh. J Health Popul Nutr 2012;30(2):193-204

16. Patel V, Rahman A, Jacob KS, Hughes $M$ Effect of maternal mental health on infant growth in low income countries: new evidence from South Asia. BMJ. 2004;328(7443):820-823

17. Rahman A, Bunn J, Lovel H, Creed F. Maternal depression increases infant risk of diarrhoeal illness-a cohort study. Arch Dis Child. 2007; 92(1):24-28

18. Aboud FE, Singla DR, Nahil Ml, Borisova I. Effectiveness of a parenting program in Bangladesh to address early childhood health, growth and development. Soc Sci Med. 2013;97:250-258

19. Baker-Henningham H, Powell C, Walker S, Grantham-McGregor S. The effect of early stimulation on maternal depression: a cluster randomised controlled trial. Arch Dis Child. 2005; 90(12):1230-1234

20. Aboud FE, Yousafzai AK. Global health and development in early childhood. Annu Rev Psychol. 2015;66: 433-457

21. Engle PL, Fernald LC, Alderman H, et al; Global Child Development Steering Group. Strategies for reducing inequalities and improving developmental outcomes for young children in low-income and middleincome countries. Lancet. 2011; 378(9799):1339-1353

22. Yousafzai AK, Rasheed MA, Rizvi A, Armstrong R, Bhutta ZA. Effect of integrated responsive stimulation and nutrition interventions in the Lady Health Worker programme in Pakistan on child development, growth, and health outcomes: a cluster-randomised factorial effectiveness trial. Lancet. 2014 384(9950):1282-1293

23. Hafeez A, Mohamud BK, Shiekh MR, Shah SAl, Jooma R. Lady Health Workers programme in Pakistan: challenges, achievements and the way forward. J Pak Med Assoc. 2011;61(3): 210-215

24. Gowani S, Yousafzai AK, Armstrong R, Bhutta ZA. Cost effectiveness of responsive stimulation and nutrition interventions on early child development outcomes in Pakistan. Ann N Y Acad Sci. 2014;1308:149-161
25. United Nations Children's Fund and World Health Organization. Care for Child Development: Improving the Care for Young Children. 2012. Available at: http:// www.who.int/maternal_child_ adolescent/documents/care_child_ development/en. Accessed February 20, 2015

26. Homans GC. The Human Group. New York, NY: Harcourt, Brace \& World; 1950

27. Pakistan Medical Research Council. National Nutrition Survey 2011. Islamabad, Pakistan: Nutrition Wing, Cabinet Division, Government of Pakistan; 2013

28. Fernald LHC, Kariger P, Engle P, Raikes A. Examining Early Child Development in Low-Income Countries: A Toolkit for the Assessment of Children in the First Five Years of Life. Washington, DC: The World Bank; 2009

29. Rasheed MA, Yousafzai AK. The development and reliability testing of an observation tool for assessing mother-child interaction in field studies- Experience from Pakistan In: The 16th European Conference on Developmental Psychology, Lausanne, Switzerland; September 3-7, 2013

30. Landry SH, Smith KE, Swank PR Responsive parenting: establishing early foundations for social, communication, and independent problem-solving skills. Dev Psychol. 2006; 42(4):627-642

31. Caldwell B, Bradley R. Home Observation for Measurement of the Environment. Little Rock, AR: University of Arkansas; 1984

32. United Nation's Children's Fund. Multiple Indicator Cluster Surveys (MICS). 2014. Available at: http://www. unicef.org/statistics/ind. Accessed April 17, 2014

33. World Health Organization. Indicators for assessing infant and young child feeding practices: conclusions from a consensus meeting held 6-8 November, 2007 in Washington DC USA. Geneva, Switzerland: 2007. Available at: http://www.who.int/ nutrition/publications/infantfeeding/ 9789241596664/en. Accessed February 20, 2015 
34. Beusenberg M, Orley J. A User's Guide to the Self Reporting Questionnaire (SRQ). Geneva, Switzerland: World Health Organization; 1994

35. Rahman A, Iqbal Z, Lovel H, Shah MA. Screening for postnatal depression in the developing world: a comparison of the WHO Self-Reporting Questionnaire (SRQ-20) and the Edinburgh Postnatal Depression Screen (EPDS). J Pak Psychiatr Soc. 2005;2:69-75

36. Rahman A, Iqbal Z, Waheed W, Hussain N. Translation and cultural adaptation of health questionnaires.
$J$ Pak Med Assoc. 2003;53(4):

142-147

37. Rahman A, Iqbal Z, Roberts C, Husain N. Cluster randomized trial of a parentbased intervention to support early development of children in a low-income country. Child Care Health Dev. 2009; 35(1):56-62 


\section{Parenting Skills and Emotional Availability: An RCT \\ Aisha K. Yousafzai, Muneera A. Rasheed, Arjumand Rizvi, Robert Armstrong and Zulfiqar A. Bhutta \\ Pediatrics originally published online April 13, 2015;}

\section{Updated Information \&} Services

Supplementary Material

Permissions \& Licensing

Reprints including high resolution figures, can be found at:

http://pediatrics.aappublications.org/content/early/2015/04/08/peds.2 $014-2335$

Supplementary material can be found at:

http://pediatrics.aappublications.org/content/suppl/2015/04/08/peds.2 014-2335.DCSupplemental

Information about reproducing this article in parts (figures, tables) or in its entirety can be found online at:

https://shop.aap.org/licensing-permissions/

Information about ordering reprints can be found online: http://classic.pediatrics.aappublications.org/content/reprints

Pediatrics is the official journal of the American Academy of Pediatrics. A monthly publication, it has been published continuously since. Pediatrics is owned, published, and trademarked by the American Academy of Pediatrics, 141 Northwest Point Boulevard, Elk Grove Village, Illinois, 60007. Copyright (C) 2015 by the American Academy of Pediatrics. All rights reserved. Print ISSN: . 


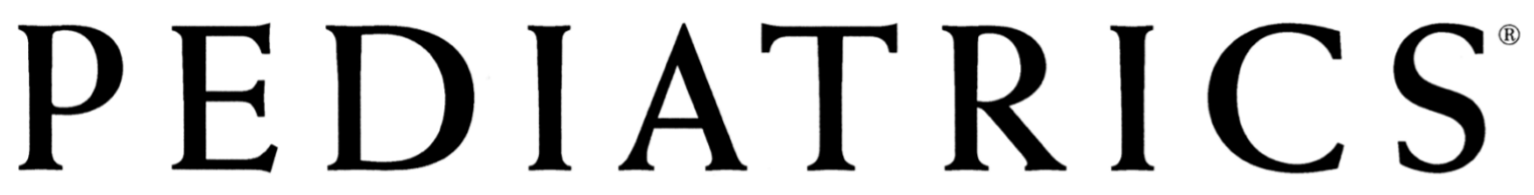

OFFICIAL JOURNAL OF THE AMERICAN ACADEMY OF PEDIATRICS

Parenting Skills and Emotional Availability: An RCT

Aisha K. Yousafzai, Muneera A. Rasheed, Arjumand Rizvi, Robert Armstrong and Zulfiqar A. Bhutta

Pediatrics originally published online April 13, 2015;

The online version of this article, along with updated information and services, is located on the World Wide Web at:

http://pediatrics.aappublications.org/content/early/2015/04/08/peds.2014-2335

Pediatrics is the official journal of the American Academy of Pediatrics. A monthly publication, it has been published continuously since. Pediatrics is owned, published, and trademarked by the American Academy of Pediatrics, 141 Northwest Point Boulevard, Elk Grove Village, Illinois, 60007. Copyright (C 2015 by the American Academy of Pediatrics. All rights reserved. Print ISSN: . 